\title{
Abdominal catheter with resistance can be an alternative in hydrocephalic children, when shunt implantation is impossible due to prematurity or extreme hydrocephalus Kai Arnell* and Pelle Nilsson
}

Address: Dept Neurosurgery, University Hospital, 75185 Uppsala, Sweden

Email: Kai Arnell* - kai.arnell@surgsci.uu.se

* Corresponding author

from 53rd Annual Meeting of the Society for Research into Hydrocephalus and Spina Bifida Belfast, UK. 24-27 June 2009

Published: 27 November 2009

Cerebrospinal Fluid Research 2009, 6(Suppl 2):SI7 doi:I0.II86/1743-8454-6-S2-SI 7

This abstract is available from: http://Www.cerebrospinalfluidresearch.com/content/6/S2/SI 7

(C) 2009 Arnell and Nilsson; licensee BioMed Central Ltd.

\section{Background}

Preterm infants have a risk of developing postnatal haemorrhage and secondary hydrocephalus. In these children and those with an extreme hydrocephalus shunting is a problem due to thin vulnerable skin and very wide sutures respectively. Tapping or external ventricular drainage is a temporary treatment with risk of developing an intra-ventricular infection.

\section{Materials and methods}

Between 1977 and 2008 six hydrocephalic infants were shunted with a pre-bent ventricular catheter and an abdominal catheter with resistance. Four of the infants were prematurely born with a postnatal haemorrhage and secondary hydrocephalus and two born at term with a giant hydrocephalus. The medical records of these children were retrospectively reviewed with respect to gestational age and weight at first operation, ICP, length of catheters, complications and age at valve implantation

\section{Results}

Four of the infants were prematurely born at 24 to 28 gestational weeks and the other two at 39 and 41 respectively. All children had thin and vulnerable skin at operation. The premature born were shunted at a weight between $700 \mathrm{~g}-1900 \mathrm{~g}$ and a corrected age of 28 to 36 weeks. The other two were shunted at the age of 43 and 40 weeks weighing 3800 and $4100 \mathrm{~g}$ respectively. At operation all infants had a bulging fontanel and the head circumfer- ence varied from +3 to +8 SD. ICP varied from $9-20 \mathrm{~cm}$ $\mathrm{H} 2 \mathrm{O}$. One prematurely born infant was not kept in supine position postoperatively and developed a subdural haemorrhage. It was treated conservatively. A real shunt was inserted at revision due to short ventricular catheter or desire to change the opening pressure at the age of 3.5 months to 6.5 years

\section{Conclusion}

Pre-bent ventricular catheter and an abdominal catheter with resistance is a useful alternative, when a shunt is impossible to implant. It is important to follow fontanel tonus and keep a supine position postoperatively in order to reduce rapid drainage and a risk for postoperative haemorrhage. 